\title{
Investigating ICT skills and the use of audio media in distance education among teachers and students: the case of Mountains of the Moon University in Uganda
}

\author{
Mark Kaahwa (1,2), Chang Zhu (1), Moses Muhumuza (2) \\ (I) Psychology and Educational Sciences, Vrije Universiteit Brussel, Belgium \\ (2) Center for Action and Applied Research for Development, Mountains \\ of the Moon University, Uganda
}

\begin{abstract}
Although teachers' and students' ICT skills have previously been investigated, there is still scant information about their ICT skills in relation to audio media as an independent medium of instruction. This study, therefore, investigates the ICT skills of higher education distance students (HEDS) and teachers regarding the use of audio media. We used purposive sampling technique to select HEDS $(\mathrm{n}=8 \mathrm{I})$ and teachers $(\mathrm{n}=4 \mathrm{I})$. Data were collected using a structured questionnaire. The results indicate that on average, teachers' and students' levels of confidence regarding computer use are $76 \%$ and $68 \%$ respectively. The results on general ICT knowledge indicate that $52 \%$ of students rated themselves as having either good or excellent ICT skills compared to $49 \%$ of teachers. The results also show that both students and teachers use MP3 players on a regular basis. However, results reveal that they are ambivalent regarding recording and editing of audio content. Generally, the findings of this study demonstrate that teachers and students can adopt audio media in distance education.
\end{abstract}

Key words: audio media, ICT skills, distance education, medium of instruction, Moodle platform

\section{Introduction}

In practical terms it is unwise to introduce audio media as a medium of instruction in distance education to teachers and students without knowing their levels of ICT skills. This is because, as this study will argue, audio media require the use of ICTs such as computers, radio, smartphones, iPods and other $\mathrm{MP}_{3}$ players. Although previous studies have investigated teachers' and students' levels of ICT usage, this has been largely done in a general way. Limited research has been done especially in the Ugandan context on the investigation of ICT skills in relation to the use of audio media as an independent medium of instruction. In this study, audio media is operationally defined as the use of interactive 
radio instruction supplemented by recorded lectures uploaded onto a Moodle platform (podcasts). In the present study ICT skills refers to teachers' and students' ability to use basic computer applications. This includes but is not limited to being able to record, edit, upload and download lecture content and the ability to use other electronic mobile devices (e.g. smartphones, iPods and other $\mathrm{MP}_{3}$ players). Hennessy (2010), observes that for many teachers and students in Uganda, the computer and the internet are still a mystery. This situation is even worse in the rural areas, where most Ugandans (about 8o percent) live without electricity and connectivity to the global information network. These communities are unable to reap the numerous benefits of ICT. In the study by Bindu (2017), teachers who are not ICT skilled may be unable to contribute to ICT integrated learning. The problem is compounded by the lack of proper training given to teachers to enhance their use of ICT as a pedagogical tool. Studies around the world show that ICTs help to broaden access to education as well as improve learning outcomes. At the same time, research indicates that success in using ICT in education depends on teachers' skills in integrating ICT and pedagogy (Orinda, 2015). A previous study by Ali et al. (2013) also points out that teachers' computer competence is a major predictor of integrating ICT in teaching. Evidence from this study suggests that the majority of teachers who reported negative or neutral attitudes towards the integration of ICT into teaching and learning processes lacked knowledge and skills that would allow them to make "informed decision regarding the use of ICTs in teaching."

Even though the pioneers of distance education used the best technology of their day, the postal system, to open educational opportunities to people who wanted to learn but were not able to attend conventional schools, this served only a small number of students. Distance teaching and learning in the 2Ist Century require both teachers and students to have some levels of ICT proficiency. This is because of the modern e-pedagogical methodologies that have been introduced in distance education (Sumande, 2016). The findings of the study conducted by Neema-Abooki and Nakintu (2015) reveal that there is an urgent need for teachers to have adequate knowledge of ICT if they are to have a competitive edge in the world of education today. To this end, a new syllabus on Computer Science was recently developed for primary schools in Uganda. For this syllabus to be effectively implemented, the teachers involved must have a knowledge of and experience in computers.

In the reviewed literature, authors investigated the necessity of ICT skills for education in rather a general way. The present study sought to investigate teachers' and students' ICT skills in relation to the use of audio media in distance education; and therefore, in this paper we discuss the following questions:

I. What are the basic ICT skills among students and teachers regarding the use of audio media as a medium of instruction in distance education?

2. What are the teachers' and students' levels of confidence and self-evaluation of their own ICT skills?

3. What are the teachers' and students' levels regarding perceived ease of use of computer applications and frequency of use of $\mathrm{MP}_{3}$ players? 


\subsection{Basic ICT skills among students and teachers in relation to the use of audio media}

In the United Kingdom, a teacher is now an e-Teacher, who is fully equipped with the knowledge of different digital gadgets in preparing for the lecture, delivering it to students, as well as in evaluating and assessing educational goals. ICTs are now widely used in university classrooms both by lecturers and students in the United States of America. University students frequently have access to computers in class. This calls for both teachers and students to possess at least basic ICT skills if they are to integrate them (ICTs) in the teaching and learning process (Orinda, 2015). Studies have found that for effective technology integration, teachers need to have technological knowledge, which has become one of the basic skills in teaching. However, such knowledge is not enough for effective teaching with technology. Teachers must know about various types of hardware as well as software and the ways to integrate them into their instruction (Varol 2013). The findings of the study conducted by Yildirim (2007), indicate that teachers largely use ICT for creating handouts and tests, rather than using it to promote students' critical thinking skills and to foster their higher order cognitive abilities. Due to a lack of pedagogical support, teachers report the lowest frequency of use of the instructional software. Additionally, teachers feel most competent in word processing, whereas they feel least competent in the use of the instructional software. In the reviewed literature, the authors do not link ICT to audio media usage in distance education and thus in this study, we investigated whether teachers and students have ICT skills required to use of audio media in distance education.

\subsection{Teachers' and students' levels of confidence and self-evaluation of their own ICT skills}

The research by Kilic (2017) observed that determining teachers' self- confidence levels regarding the use of ICT during the educational process is important, as they influence the effective use of ICT in the learning-teaching process. Kilic observes that teachers use technology in their classes more as their self-confidence regarding the use of ICT increases, which in turn helps to increase their comfort with ICT. In the study by Tasir et al. (2012), the findings show that Malaysian teachers have a high confidence level using ICT. In terms of satisfaction, the study finds that most ministries are content with the ICT training programmes examined. Previous studies indicate that research on teacher integration of computers has generally reported very little impact on classroom teaching and learning. Explanations offered for this include the influence of teacher confidence and expertise, and teachers' beliefs about the potential for ICT to make a difference to student learning. There are close relationships between many of the identified barriers to ICT use, and any factors influencing one barrier are likely also to influence several other barriers. For example, teacher confidence is directly affected by levels of personal access to ICT, levels of technical support and the quality of training available (Jamieson-Proctor et al., 2006). According to Cretchley (2007), computer confidence determines how well students perform in a learning environment that requires interaction with computers. His findings reveal that careful and appropriate use of professional software does indeed enliven learning for most students. Moreover, despite careful and nurturing support for 
use of the software, students with low computer confidence levels feel threatened and disadvantaged by computer laboratory tasks. In a study by Paraskeva et al. (2005), it is pointed out that Greek teachers' self-efficacy is moderate to high, because of their high sense of general self-efficacy and confidence in their abilities, combined with their desire to master and use modern technologies.

\subsection{Perceived ease of use of computer applications and frequency of use of $M P_{3}$ players by} teachers and students

Perceived ease-of-use of ICT is a factor that influences the adoption and use of Information technology or information and communication devices. Ease-of-use of ICT is the extent to which the electronic device or personal digital assistants can be used with few or no constraints. All things being equal, computer applications that are perceived to be easy by users will likely be accepted and used by the same users (Abiola, 20r6). Students might perceive the computer as an easily accessible device, which lends itself to effortless usage; when they have a habit of viewing computers as a means of entertainment, they might tend to avoid the association of computers with strenuous learning and studying (Schlag \& Imhof, 2017). Teo (2009) found that perceived ease of use is a significant determinant of the attitude and intention to use technology among student teachers. This view is supported by previous research that shows that perceived ease of use is a factor that directly affects students' attitudes (e.g. Sumak et al. 20II). Additionally, Chih-Hong et al. (2012) point out that learners usually prefer to use e-teaching to assist with their course work and assignments if they find it easy to use. Therefore, it is vital to make e-teaching platforms easy to interact with, such as through clear and simple navigation buttons of the whole system. Such measures increase student perception of the ease of use of technology.

Regarding frequency of use of $\mathrm{MP}_{3}$ players by teachers and students, studies indicate that listening to iPods is the most popular day-to-day activity among undergraduate college students of Auburn University in the United States of America. The reported recreational and relaxation benefits associated with iPods have clearly created a new culture infused with music among college students (Hoover, et al., 20I0). In the recent research of Li (2015), findings indicate a widespread use of computers, cell phones, and social media, as well as frequent access to the internet among urban adolescents from lower social economic status families. About $70 \%$ of the respondents used cellphones on a daily basis, and over $55 \%$ used desktop and laptop computers every day or at least once every 2-3 days. Furthermore, the research of Williams (2014), indicates that most agriculture teachers had access to computers either in their classroom or at another location in the school for student use. Students used these computers several times a year or 2-4 times a month. On the other hand, almost half of the agriculture teachers did not have access to tablet computers. Aristizabal (2009) points out that most educators undoubtedly have noticed that many young people are connected to their iPods or $\mathrm{MP}_{3} / \mathrm{MP}_{4}$ players on a daily basis. A teacher will also notice that listening to these devices has little negative impact on a student's concentration. If the students' level of productivity is affected at all, it 
is not a significant amount. These observations suggest that the wide use of such devices can be exploited for educational purposes (and not only to listen to music). This is further affirmed by Stiler (2007), who observes that teachers and students in other content areas may benefit from using $\mathrm{MP}_{3}$ players to download audio clips containing content-specific information in their subject areas.

The literature reviewed indicates that although the use of audio media as a medium of instruction has been growing in the recent years, there has been limited research that investigates the teachers' and students' ICT skills in relation to audio media usage in distance education as an independent medium of instruction. Previous studies mainly examined teachers' and students' competencies in relation to the use of ICTs in conventional teaching. The main objective of this investigation, therefore, is to investigate teachers' and students' ICT skills regarding the use of audio media as an independent medium of instruction in a Ugandan context.

\subsection{Theoretical framework}

This study is guided by situated cognition theory, which is sometimes referred to as "situated learning". It is a learning theory that posits the idea that learning occurs only when situated within a specific context, and that learning takes place in a learning community or community of practice, where the learners take an active role. This involves a process of interaction between the learners within the community, the tools available within the specific situation and the physical world. It is within this active participation and interaction (whether with tools, artifacts or other people) that knowledge is located. Therefore, knowledge evolves as the learners participate and interact with the new situation. Cognition is linked to the action the learners in the community take, whether it is physical in nature or a reflective process within the learners themselves (Myers \& Wilson, 2000). In the present study, the investigation of teachers' and students' ICT skills is situated in a context of audio media. During the various audio media workshops, teachers and students were actively involved in creating user accounts for a Moodle platform, recording, editing audio content, uploading and downloading audio lectures from the platform. The theory postulates that learning takes place through doing and thus even during solitary moments when students were listening to the podcasts, they continued being active by summarizing audio content in their notebooks, by pausing, forwarding and generally reflecting on the podcasts.

\section{Methods}

\subsection{Research design}

The present study is quantitative in nature. In particular, it is a case study of the situation at Mountains of the Moon University in Uganda. As such it is part of a larger Ph.D. study assessing the effectiveness of audio media in distance and community education in Uganda. Quantitative methods of data collection and analysis are employed in this study. Martyn (2008) points out that this kind of quantitative research design is an excellent way 
of finalizing results. After statistical analysis the results, can be legitimately discussed and published.

\subsection{Sample and sampling procedure}

During session one for the academic year 2015-2016, the following categories were invited to participate in this study: Bachelor of Education students in year two from the School of Education, Bachelor of Science in Public Health year one and year two students from the School of Health Sciences, and teachers in the respective schools. A purposive sampling technique was used to select 8I students and 4I teachers from the two Schools. Teachers and students were selected because they were teaching and studying in the distance programme respectively. Participants were also required to have mobile electronic devices such as smartphones, laptop computers, iPods or other MP3 players. Students and teachers who did not own portable media devices or any other $\mathrm{MP}_{3}$ players and were not involved in distance education were excluded from the present study. Before filling in the questionnaires and attending live interactive radio classes, participants attended audio media workshops focusing on script writing, recording, editing recording, uploading, downloading podcasts, signing into and familiarizing themselves with the Moodle platform. After the workshops, higher education distance students (HEDS) were invited to attend live interactive radio lectures. Although we arranged use of a classroom furnished with a home theater that transmitted the live interactive radio lectures for students, they were free to attend from different geographical spaces and learning centers. Live interactive radio lectures were allocated nine hours for each course unit, the time normally allocated for face-to-face teaching in the modular distance approach. Learners were given a chance to ask questions or make contributions by either calling in through a studio line or sending WhatsApp messages to the instructor in the studio. After live radio lectures, HEDS studied and revised content using podcasts downloaded from the Moodle platform. Thirty-five short lectures of 25 to 30 minutes were recorded and uploaded onto the Moodle platform.

\subsection{Research instrument}

We used a questionnaire that was in part based on the study of Walls et al. (2010). The rest of the items in the questionnaire were self-developed by the researchers. The questionnaire was divided into the following sections: ICT skills in relation to radio use by teachers and students, general level of confidence regarding computer use by teachers and students, perceived ease of use of computer applications, self-evaluation regarding general computer knowledge by teachers and students, frequency of use of $\mathrm{MP}_{3}$ players by teachers and students, ICT skills in relation to podcast management and teachers' and students' skills in management of basic computer applications. To ensure content validity of the survey, the first author produced the initial draft, which was sent to co-authors. In their turn, the co-authors made all the possible corrections and removed vague questions. We further piloted the instrument among twelve participants. The final version was administered to all the participants in the study. 


\subsection{Material \& Equipment}

The study used KRC FM Radio "The farmer's voice" to broadcast live interactive radio lectures for HEDS. Wave Pad sound editor was used to edit recorded lectures. Wave Pad sound editor is a full-featured professional sound editor for Windows that facilitates the creation and editing of voice and other audio recordings.

\subsection{Participants}

We used 8I HEDS ( 46 males and 35 females) and 4I teachers ( 23 males and I8 females) from the School of Education and the School of Health Sciences. Participants were in the following age brackets: 20 to 29 years (17.3\%), 30 to 39 years (42.0\%), 40 to 49 years $(36 \%)$ and 50 years and above (4.9\%). A total of I 22 participants were included in the present study.

\subsection{Reliability of the instrument}

To measure the internal consistency of items, we ran the reliability analysis and the results are indicated in Table $\mathrm{I}$.

\begin{tabular}{l|r|r} 
Item & No. of items & $\begin{array}{c}\text { Cronbach's } \\
\text { alpha }\end{array}$ \\
\hline ICT skills in relation to radio use by teachers and students. & 04 & .68 \\
\hline $\begin{array}{l}\text { Teachers' and students' competences regarding knowledge } \\
\text { of computer applications. }\end{array}$ & Io & I4 \\
\hline $\begin{array}{l}\text { Teachers' and students' skills regarding management of } \\
\text { basic computer applications. }\end{array}$ & 05 & .809 \\
\hline $\begin{array}{l}\text { ICT skills in relation to podcast management by teachers } \\
\text { and students. }\end{array}$ & 03 & .81 I \\
\hline $\begin{array}{l}\text { General level of confidence regarding computer use by } \\
\text { teachers and students. }\end{array}$ & & .694 \\
\hline $\begin{array}{l}\text { Self-evaluation regarding general computer knowledge by } \\
\text { teachers and students. }\end{array}$ & 04 & .838 \\
\hline $\begin{array}{l}\text { Perceived ease of use of computer applications by students } \\
\text { and teachers. }\end{array}$ & I2 & .840 \\
\hline Frequency of use of MP3 players by teachers and students. & 09 & .837 \\
\hline Overall Alpha & $6 \mathbf{1}$ & .788 \\
\hline
\end{tabular}

Table 1: Reliability results for the instrument.

According to the information in the table above, apart from the two scales where the reliability coefficient is slightly below .07, the rest of the scales are above the recommended alpha and this implies that the instrument was reliable for use. 


\section{Results}

3.1. ICT skills in relation to radio use by teachers and students

We examined teachers' and students' ICT skills in relation to radio use. The results in Table 2 indicate that generally both teachers and students have the required ICT skills needed to use the radio in distance education. This is mainly because there is no special training required to use the radio, as indicated by teachers ( $80.5 \%$ ) and students (7I.6\%). The majority of teachers $(87.8 \%)$ and students (93.8\%) indicated that they can turn on a radio set. Results show that teachers and students are not as familiar with radio use in teaching and learning, as shown by a large percentage of teachers $(65.9 \%)$ and students $(65.4 \%)$ respectively.

\begin{tabular}{l|r|c|r|r}
\multirow{2}{*}{ Statement } & \multicolumn{2}{|c|}{ Yes (\%) } & \multicolumn{2}{c}{ No (\%) } \\
\cline { 2 - 5 } & \multicolumn{1}{|c|}{ T's } & \multicolumn{1}{c}{ S's } & \multicolumn{1}{c}{ T's } & \multicolumn{1}{c}{ S's } \\
\hline Do you know how to turn on a radio set? & 87.8 & 93.8 & I2.2 & 6.2 \\
\hline Did you receive any special training? & I9.5 & 28.4 & 80.5 & 7 I.6 \\
\hline Are you able to search for the station you wish to listen to? & 95.1 & 88.9 & 4.9 & II.I \\
\hline Have you before taught or been taught through the radio? & 34.1 & 34.6 & 65.9 & 65.4 \\
\hline $\begin{array}{l}\text { Have you ever presented an educational programme on the } \\
\text { radio? }\end{array}$ & 29.3 & I4.8 & 70.7 & 85.2 \\
\hline
\end{tabular}

Note: T's for teachers \& S's for students.

Table 2: Percentages of ICT skills in relation to radio use by teachers and students $(n=122)$.

\subsection{Teachers' and students' competences regarding knowledge of computer applications}

In this study, we investigate teachers' and students' competencies regarding knowledge of computer applications. The average results for teachers' and students' competencies are $71.22 \%$ and $68.4 \%$ respectively (see Table 3 ). Regarding the question of whether they know how to use a computer for teaching/learning purposes, the majority of teachers $(63.4 \%)$ and students $(77.8 \%)$ agreed that they do. They also agreed that they find it easy to learn something by reading it from a computer screen $(75.6 \%$ of teachers and 85.2 of students). Results also indicate that $78.0 \%$ of teachers and $64.2 \%$ of students can access computers connected to the internet while at school. 


\begin{tabular}{l|r|r|r|r}
\multirow{2}{*}{ Statement } & \multicolumn{2}{|c|}{ Yes (\%) } & \multicolumn{2}{c}{ No (\%) } \\
\cline { 2 - 5 } & \multicolumn{1}{c}{ T's } & \multicolumn{1}{c}{ S's } & \multicolumn{1}{c}{ T's } & \multicolumn{1}{c}{ S's } \\
\hline Do you know how to connect a computer to the internet? & 90.2 & 79.0 & 9.8 & 21.0 \\
\hline Do you have an e-mail account? & 92.7 & 90.1 & 7.3 & 9.9 \\
\hline Do you have a personal homepage on the Web? & I6.3 & I0.9 & 83.8 & 89.8 \\
\hline $\begin{array}{l}\text { Do you understand the basic functions of computer } \\
\text { hardware components? }\end{array}$ & 73.2 & 76.5 & 26.8 & 23.5 \\
\hline $\begin{array}{l}\text { Do you know how to use keyboard shortcuts? } \\
\text { Do you use a computer connected to the internet at school? }\end{array}$ & 78.0 & 64.2 & 22.0 & 35.8 \\
\hline $\begin{array}{l}\text { Do you know how to use a computer for teaching/learning } \\
\text { purposes? }\end{array}$ & 63.4 & 77.8 & 36.6 & 22.8 \\
\hline $\begin{array}{l}\text { Do you find it easy to learn something by reading it from a } \\
\text { computer screen? }\end{array}$ & 75.6 & 85.2 & 24.4 & I4.8 \\
\hline $\begin{array}{l}\text { Do you use CD-ROMs to supplement your learning or } \\
\text { teaching? }\end{array}$ & 53.7 & 39.5 & 46.3 & 60.5 \\
\hline $\begin{array}{l}\text { Do you know how to use Web sites to supplement your } \\
\text { learning? }\end{array}$ & 65.9 & 63.0 & 34.1 & 37.0 \\
\hline
\end{tabular}

Note: T's for teachers \& S's for students.

Table 3: Percentages of teachers' and students' competences regarding computer applications ( $n=122)$.

\subsection{Teachers' and Students' skills in the management of basic computer applications}

We examined teachers' and students' skills in the management of basic computer applications. The results in Table 4 indicate that on average $79 \%$ of teachers and $74 \%$ of students have skills regarding the management of basic computer applications. All teachers and $96.3 \%$ of students can properly turn on and shut down a computer. $73.2 \%$ of teachers and $66.7 \%$ of students can move a file from a hard drive to a USB drive. However, both teachers $(5 \mathrm{I} .2 \%)$ and students $(64.2 \%)$ were found to lack the required skills for recording and editing sounds. At the same time both teachers and students have the required skills to manage and store files, as indicated by $85.4 \%$ of teachers and $77.8 \%$ of students. 


\begin{tabular}{|c|c|c|c|c|}
\hline \multirow[b]{2}{*}{ Statement } & \multicolumn{2}{|c|}{ Yes $(\%)$} & \multicolumn{2}{|c|}{ No $(\%)$} \\
\hline & T's & S's & T's & S's \\
\hline Can you properly turn on and shut down a computer? & I00 & 96.3 & 0.0 & $3 \cdot 7$ \\
\hline $\begin{array}{l}\text { Can you minimize, maximize and move Windows on } \\
\text { the desktop? }\end{array}$ & 90.2 & 91.4 & 9.8 & 8.6 \\
\hline $\begin{array}{l}\text { Can you perform file management including deleting and } \\
\text { renaming files etc.? }\end{array}$ & 80.5 & 77.8 & 19.5 & 22.2 \\
\hline Can you use a 'search' command to locate a file? & 75.6 & $8 \mathrm{I} .5$ & $24 \cdot 4$ & 18.5 \\
\hline Can you scan disks for viruses? & 65.9 & $69 . \mathrm{I}$ & $34 \cdot \mathrm{I}$ & 30.9 \\
\hline Can you move a file from a hard drive to a USB drive? & 73.2 & 66.7 & 26.8 & $33 \cdot 3$ \\
\hline Can you record and edit sounds? & 48.8 & 35.8 & $5 \mathrm{I} .2$ & 64.2 \\
\hline Can you create a basic Word document? & 82.9 & 72.8 & I7.I & 27.2 \\
\hline Can you copy, cut and paste text into a document? & 82.9 & 80.2 & I7.I & I9.8 \\
\hline Can you change font style and size in a document? & 82.9 & $8 \mathrm{I} \cdot 5$ & I7.I & I8.5 \\
\hline $\begin{array}{l}\text { Can you send and receive attachments through e-mail } \\
\text { messages? }\end{array}$ & 82.9 & 76.5 & $\mathrm{I} 7 \cdot \mathrm{I}$ & $23 \cdot 5$ \\
\hline $\begin{array}{l}\text { Can you search for information online using a Web search } \\
\text { engine? }\end{array}$ & 75.6 & 69.1 & $24 \cdot 4$ & 30.9 \\
\hline $\begin{array}{l}\text { Can you download and save files from the Web (e.g., text, } \\
\text { graphic, PDF files)? }\end{array}$ & 82.9 & 65.4 & I7.I & 34.6 \\
\hline Can you manage and store files? & 85.4 & 77.8 & $\mathrm{I} 4.6$ & 22.2 \\
\hline
\end{tabular}

Note: T's for teachers \& S's for students.

Table 4: Percentages of teachers' and students' skills on management of basic computer applications ( $n=122)$.

\subsection{ICT skills in relation to podcast management}

We investigated ICT skills in relation to podcast management by teachers and students. The results reveal that teachers have more ICT skills regarding the management of podcasts than students (see Table 5 ). The majority of teachers (75.6\%) and a small proportion of the students (28.4\%) know how to make podcasts, $70.7 \%$ of teachers and $40.7 \%$ of students know how to upload a podcast on the internet. As with teachers, students have the required ICT skills to download podcasts onto their mobile electronic devices, $73.2 \%$ and $67.9 \%$ respectively. They can also find podcasts saved on their mobile devices and read them $-63.0 \%$ of teachers and $66.7 \%$ of students. 


\begin{tabular}{|c|c|c|c|c|}
\hline \multirow[b]{2}{*}{ Statement } & \multicolumn{2}{|c|}{ Yes (\%) } & \multicolumn{2}{|c|}{ No (\%) } \\
\hline & T's & S's & T's & S's \\
\hline Do you know how to make a podcast? & 75.6 & 28.4 & 24.4 & 71.6 \\
\hline $\begin{array}{l}\text { Do you know how to upload a podcast on the Moodle } \\
\text { platform? }\end{array}$ & 70.7 & 40.7 & $29 \cdot 3$ & $59 \cdot 3$ \\
\hline $\begin{array}{l}\text { Do you know how to download podcasts from the Moodle } \\
\text { platform onto your mobile device? }\end{array}$ & 73.2 & 67.9 & 26.8 & 32.1 \\
\hline Do you know how to save podcasts on your mobile device? & 75.6 & 63.0 & 24.4 & 37.0 \\
\hline $\begin{array}{l}\text { Do you know how to find and open a podcast saved on your } \\
\text { computer and listen? }\end{array}$ & 85.4 & 66.7 & I4.6 & $33 \cdot 3$ \\
\hline
\end{tabular}

Note: T's for teachers \& S's for students.

Table 5: Percentages of ICT skills in relation to podcast management $(n=122)$.

\subsection{General level of confidence regarding computer use by teachers and students}

According to the results in Table 6 , on average, $76 \%$ of teachers and $68 \%$ of students have high levels of confidence regarding computer use. $78.1 \%$ of teachers and $71.6 \%$ of students feel confident using a computer on their own with only $19.5 \%$ of teachers and II.I\% of students who do not feel confident using a computer on their own.

\begin{tabular}{|c|c|c|c|c|c|c|}
\hline \multirow[b]{2}{*}{ Statement } & \multicolumn{2}{|c|}{ Rejected (\%) } & \multicolumn{2}{|c|}{ Uncertain (\%) } & \multicolumn{2}{|c|}{ Accepted (\%) } \\
\hline & T's & S's & T's & S's & T's & S's \\
\hline $\begin{array}{l}\text { Do you feel confident to use a computer } \\
\text { when someone is there to support you? }\end{array}$ & 22 & I6.I & 2.4 & 9.9 & 75.6 & 74.1 \\
\hline $\begin{array}{l}\text { Do you feel confident to use a computer on } \\
\text { your own? }\end{array}$ & 19.5 & II.I & 2.4 & $17 \cdot 3$ & 78.1 & 71.6 \\
\hline $\begin{array}{l}\text { Do you feel confident to use a computer to } \\
\text { help colleagues/students? }\end{array}$ & 24.4 & 23.4 & 2.4 & I9.8 & 73.1 & 56.8 \\
\hline
\end{tabular}

Note: T's for teachers \& S's for students.

Table 6: Percentages of the general level of confidence regarding computer use by teachers and students ( $n=122)$.

\subsection{Teacher and student self-evaluation regarding general computer knowledge}

In the teacher and student self-evaluation in Table 7 the respondents indicating that their general computer knowledge is good amounted to $29.3 \%$ for teachers; 5 I.9\% for students. $4 \mathrm{I} .5 \%$ of teachers and $38.3 \%$ of students indicated that their general computer knowledge is adequate. Only $19.5 \%$ of the teachers claimed to have excellent general computer knowledge, none of the students said they were excellent. Regarding internet literacy, generally, results indicate that both teachers and students have the required internet skills for audio media with $\mathrm{I} 4.6 \%$ of teachers and $\mathrm{I} .2 \%$ of students saying that they are excellent. The proportion of students who regarded themselves as having a high level of internet literacy is $56 \%$, compared to the teachers' $36.6 \%$. Results also indicate that 
the current typing skills of both teachers and students are above average with $5 \mathrm{I} .2 \%$ of teachers and $53.1 \%$ of students stating their skills are excellent and good.

\begin{tabular}{|c|c|c|c|c|c|c|c|c|c|c|}
\hline \multirow[b]{2}{*}{ Statement } & \multicolumn{2}{|c|}{ Excellent $\%$} & \multicolumn{2}{|c|}{ Good\% } & \multicolumn{2}{|c|}{ Adequate $\%$} & \multicolumn{2}{|c|}{ Not sure\% } & \multicolumn{2}{|c|}{ Poor $\%$} \\
\hline & T's & S's & T's & S's & T's & S's & T's & S's & T's & S's \\
\hline Your own computer literacy & $\mathrm{I} 4.6$ & 2.5 & 39.0 & 53.1 & $34 . \mathrm{I}$ & 32.1 & 2.4 & 8.6 & 9.8 & $3 \cdot 7$ \\
\hline Your own Internet literacy & I4.6 & $\mathrm{I} .2$ & 36.6 & 56.8 & 39.0 & 30.9 & 4.9 & II.I & 4.9 & 0.0 \\
\hline Your current typing skills & $\mathrm{I} 4.6$ & 0.0 & 36.6 & $53 . \mathrm{I}$ & $43 \cdot 9$ & 38.3 & 0.0 & 8.6 & 4.9 & 0.0 \\
\hline $\begin{array}{l}\text { Your own general computer } \\
\text { knowledge }\end{array}$ & 19.5 & 0.0 & $29 \cdot 3$ & 51.9 & $4 \mathrm{I} \cdot 5$ & 38.3 & 0.0 & $9 \cdot 9$ & 9.8 & 0.0 \\
\hline
\end{tabular}

Note: T's for teachers \& S's for students.

Table 7: Percentages of self-evaluation regarding general computer knowledge by teachers and students $(n=122)$.

\subsection{Perceived ease of use of computer applications by students}

Students were asked to rate statements about how easy they find the use of some computer applications. Generally, results reveal that students can use most of the computer applications with ease. According to the results, they find the use of word processing, emails, text chatting and voice chatting extremely easy. The results also indicate students have the capability to use the World Wide Web with ease, creating and resetting passwords, typing texts and playing computer games. However, results show that students find the use of multimedia (audio and video) somewhat more difficult. Table 8 illustrates the mean of items that addressed their personal responses on how easy they found the use of the indicated computer applications. The rating was done on a sevenpoint scale of extremely easy (I) to extremely difficult (7). A score of 4 would indicate mixed feelings or opinions. 


\begin{tabular}{|c|c|c|c|c|}
\hline Statement & $\mathrm{N}$ & Mean & Std. Error Mean & Std. Deviation \\
\hline How easy do you find the use of word processing? & $8 \mathrm{I}$ & I. 62 & .100 & .902 \\
\hline How easy do you find the use of email? & $8 \mathrm{I}$ & I.70 &. IIo & .993 \\
\hline How easy do you find the use of World Wide Web? & $8 \mathrm{I}$ & 2.38 & .184 & I.655 \\
\hline $\begin{array}{l}\text { How easy do you find the use of multimedia (audio } \\
\text { and video)? }\end{array}$ & $8 \mathrm{I}$ & 3.07 &. $\mathrm{I} 6 \mathrm{I}$ & I. 447 \\
\hline $\begin{array}{l}\text { How easy do you find creating and resetting the } \\
\text { password? }\end{array}$ & $8 \mathrm{I}$ & 2.23 & .179 & I.6I5 \\
\hline How easy do you find the use of graphics? & $8 \mathrm{I}$ & 3.96 & .185 & I. 662 \\
\hline How easy do you find the typing of texts? & $8 \mathrm{I}$ & 2.02 & .159 & 1.432 \\
\hline How easy do you find online discussion groups? & $8 \mathrm{I}$ & I.90 & .130 & I.I68 \\
\hline How easy do you find text chatting? & $8 \mathrm{I}$ & $\mathrm{I} .84$ &. $\mathrm{I} 35$ & I.219 \\
\hline How easy do you find voice chatting? & $8 \mathrm{I}$ & I.9I & .195 & I. 755 \\
\hline How easy do you find video conferencing? & $8 \mathrm{I}$ & $3.8 \mathrm{I}$ & .184 & I. 652 \\
\hline How easy do you find the use of computer games? & $8 \mathrm{I}$ & 2.25 & .I99 & I.793 \\
\hline
\end{tabular}

Table 8: Means of students' responses regarding perceived ease of use of computer applications $(n=81)$.

\subsection{Perceived ease of use of computer applications by teachers}

We examined the perceived ease of use of computer applications by teachers. Results indicate that similar to the students, teachers find the use of word processing, e-mail, typing texts, text chatting and voice chatting extremely easy. However, results indicate that teachers are ambivalent regarding the use of multimedia (audio and video), World Wide Web and use of graphics. Generally, the survey results show that in most cases the mean was below the mid-point (4) on a seven-point scale, which indicates that teachers and students can easily apply these skills to the use of audio media in distance education. As indicated in Table 9, teachers were asked to rate statements about how easy they find the use of indicated computer applications on a seven-point scale of extremely easy (I) to extremely difficult (7). A score of 4 would indicate mixed feelings or opinions. 


\begin{tabular}{|c|c|c|c|c|}
\hline Statement & $\mathrm{N}$ & Mean & Std. Error mean & Std. Deviation \\
\hline How easy do you find word processing? & $4 \mathrm{I}$ & I.98 & .243 & I.557 \\
\hline How easy do you find the use of email? & $4 \mathrm{I}$ & I. 85 & .190 & I.2I6 \\
\hline How easy do you find the use of World wide web? & $4 \mathrm{I}$ & $4 \cdot 30$ & .282 & I. 786 \\
\hline $\begin{array}{l}\text { How easy do you find the use of multimedia (audio } \\
\text { \& video)? }\end{array}$ & $4 \mathrm{I}$ & $4 \cdot 46$ & .242 & I. $55 \mathrm{I}$ \\
\hline $\begin{array}{l}\text { How easy do you find creating and resetting } \\
\text { passwords? }\end{array}$ & $4 \mathrm{I}$ & 2.54 & .280 & I.790 \\
\hline How easy do you find the use of graphics? & $4 \mathrm{I}$ & 4.83 & .266 & I.702 \\
\hline How easy do you find typing texts? & 4I & I.56 & .188 & 1.205 \\
\hline How easy do you find online discussion group? & $4 \mathrm{I}$ & $3 \cdot 93$ & .313 & 2.005 \\
\hline How easy do you find text charting? & $4 \mathrm{I}$ & I.95 & .257 & I. 642 \\
\hline How easy do you find voice charting? & $4 \mathrm{I}$ & I.95 & .242 & $\mathrm{I} .548$ \\
\hline How easy do you find the use of video conferencing? & $4 \mathrm{I}$ & 3.12 & .328 & 2.100 \\
\hline How easy do you find the use of computer games? & $4 \mathrm{I}$ & 2.24 & .300 & I.92I \\
\hline
\end{tabular}

Table 9: Means of teachers' responses regarding perceived ease of use of computer applications $(n=41)$.

\subsection{Frequency of use of $\mathrm{MP}_{3}$ players by students}

We examined the frequency of use of $\mathrm{MP}_{3}$ players of students. Results in Table Io indicate that a majority of students frequently make use of $\mathrm{MP}_{3}$ players. In summing up the percentages of those who use $\mathrm{MP}_{3}$ players once per month, monthly, twice a week, three times a week and very many times a day, the general percentages of most aspects are above average. The highest percentage concerns watching television shows (88.9) and the lowest being listening to recorded books (46.9). In this study, 53.I\% of the students showed that they never use $\mathrm{MP}_{3}$ players to listen to recorded books at all. Using $\mathrm{MP}_{3}$ players to watch other activities related to their university education was also low, although above average with $54 \%$. These low results point to the fact that $\mathrm{MP}_{3}$ players are mostly used by students for non-academic rather than academic purposes. This is also shown by the high percentages of some responses such as listening to music (88\%), watching short video clips (85.6\%), watching movies (85.6\%) and listening to speeches/ interviews not related to one's studies (74.1\%). 


\begin{tabular}{|c|c|c|c|c|c|c|}
\hline \multirow[b]{2}{*}{ Statement } & \multicolumn{6}{|l|}{ Response } \\
\hline & ¿ั & 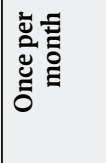 & 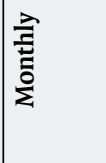 & 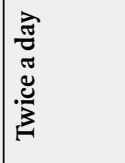 & 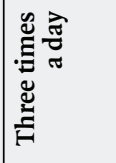 & 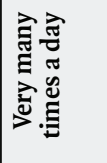 \\
\hline Listen to music & II.I\% & $8.6 \%$ & I6.0\% & $21.0 \%$ & $\mathrm{I} 4.8 \%$ & $28.4 \%$ \\
\hline Listen to recorded books & $53.1 \%$ & I $8.5 \%$ & $7 \cdot 4 \%$ & $8.6 \%$ & $4.9 \%$ & $7 \cdot 4 \%$ \\
\hline Watch news on You Tube & $30.9 \%$ & $\mathrm{I} 4.8 \%$ & $\mathrm{I} 4.8 \%$ & $\mathrm{I} 2.3 \%$ & $17 \cdot 3 \%$ & $9.9 \%$ \\
\hline Watch short video clips & $\mathrm{I} 4.8 \%$ & $21.0 \%$ & I $8.5 \%$ & $22.2 \%$ & $\mathrm{I} 2.3 \%$ & II.I\% \\
\hline Watch movies & $\mathrm{I} 4.8 \%$ & $13.6 \%$ & $13.6 \%$ & $23 \cdot 5 \%$ & $22.2 \%$ & $\mathrm{I} 2.3 \%$ \\
\hline Watch television shows & II.I\% & $8.6 \%$ & $\mathrm{I} 4.8 \%$ & $21.0 \%$ & $24.7 \%$ & $\mathrm{I} 9.8 \%$ \\
\hline Listen to class lectures & $42 \% \quad 42.0 \%$ & $22.2 \%$ & $7.4 \%$ & $9.9 \%$ & II.I\% & $7 \cdot 4 \%$ \\
\hline $\begin{array}{l}\text { Watch other activities related to my } \\
\text { university }\end{array}$ & $46 . \%$ & $\mathrm{I} 4 . \%$ & $4.9 \%$ & $9.9 \%$ & I6. \% & $7 \cdot 4 \%$ \\
\hline Listen to other non-academic audios & $23.5 \%$ & $23 \cdot 5 \%$ & $\mathrm{I} 2.3 \%$ & $\mathrm{I} 4.8 \%$ & $17.3 \%$ & $8.6 \%$ \\
\hline
\end{tabular}

Table 10: Percentage of frequency of use of $M P_{3}$ players by students $(n=81)$.

\subsection{Frequency of use of $M P_{3}$ players by teachers}

We also studied the frequency of use of $\mathrm{MP}_{3}$ players by teachers. Results indicate (Table II) that teachers use $\mathrm{MP}_{3}$ player to listen to music many times a day - 61.0\%. However, $73.2 \%$ of teachers indicated that they never use $\mathrm{MP}_{3}$ players to listen to recorded books. In summing up the percentages of those who use $\mathrm{MP}_{3}$ players once per month, monthly, twice a week, three times a week and many times a day, the general percentages of most aspects are above average, the highest being watching television shows and movies (92.7\%) and the lowest being listening to recorded lectures (66\%). Using $\mathrm{MP}_{3}$ players to watch other activities related to their university context was low though above average (59\%). These low results could mean that $\mathrm{MP}_{3}$ players are mostly used by teachers for non-academic rather than academic purposes. 


\begin{tabular}{|c|c|c|c|c|c|c|c|}
\hline \multirow[b]{2}{*}{ Statement } & \multicolumn{7}{|l|}{ Response } \\
\hline & 岂 & & 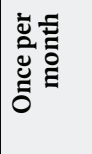 & 츨 & 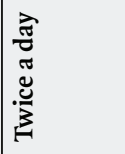 & 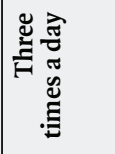 & 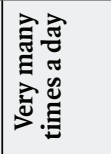 \\
\hline Listen to music & & $2.4 \%$ & $2.4 \%$ & $4.9 \%$ & $14.4 \%$ & $\mathrm{I} 4.6 \%$ & $61.0 \%$ \\
\hline Listen to recorded books & & $73.2 \%$ & $\mathrm{I} 2.2 \%$ & $9.8 \%$ & $4.9 \%$ & $0.0 \%$ & $0.0 \%$ \\
\hline Watch news on You Tube & & $\mathrm{I} 2.2 \%$ & $9.8 \%$ & $2.2 \%$ & $22.0 \%$ & $53.7 \%$ & $0.0 \%$ \\
\hline Watch short video clips & & $7 \cdot 3 \%$ & $4.9 \%$ & $7 \cdot 3 \%$ & $2.4 \%$ & $22.0 \%$ & $56.1 \%$ \\
\hline Watch movies & & $7 \cdot 3 \%$ & $7 \cdot 3 \%$ & $9.8 \%$ & $19.5 \%$ & $56.1 \%$ & $0.0 \%$ \\
\hline Watch television shows & & $9.8 \%$ & $2.4 \%$ & $2.4 \%$ & $2.4 \%$ & $3 \mathrm{I} .7 \%$ & $51.2 \%$ \\
\hline Listen to class lectures & $34.2 \%$ & $34 . \mathrm{I} \%$ & $4.9 \%$ & $4.9 \%$ & $2.4 \%$ & $\mathrm{I} 4.6 \%$ & $39.0 \%$ \\
\hline $\begin{array}{l}\text { Watch other activities related to my } \\
\text { university }\end{array}$ & & $4 \mathrm{I} \cdot 5 \%$ & $9.8 \%$ & $4 \cdot 9 \%$ & $\mathrm{I} 2.2 \%$ & $\mathrm{I} 2.2 \%$ & $19.5 \%$ \\
\hline Listen to other non-academic audios & & $48.8 \%$ & $4.9 \%$ & $7 \cdot 3 \%$ & $4.9 \%$ & $9.8 \%$ & $24.4 \%$ \\
\hline
\end{tabular}

Table 11: Percentages of frequency of use of MP3 players by teachers $(n=41)$.

\section{Discussion}

4.1. Basic ICT skills among students and teachers regarding the use of audio media as a medium of instruction in distance education

In this study, we investigate the ICT skills of teachers and students in relation to the use of audio media in distance education programmes at Mountains of the Moon University. Our study supports the results of Yildirim (2007), who points out that teachers' under-utilization of ICT in the classroom and their resistance to embedding ICT across the curriculum can be detrimental to attempts to introduce new teaching and learning technologies in education. Therefore, it is crucial to investigate teachers' ICT utilization and examine factors that contribute to their skeptical attitudes towards teaching with technology. In the present study, however, we go a step further by investigating teachers' and students' levels of ICT skills in relation to audio media in distance education. This is because teachers' and students' utilization of ICT is determined by the ICT skills they possess. With regard to radio use in distance education, results show that both teachers and students have sufficient ICT skills. This is perhaps because no special training and knowledge are required to use the radio. Most teachers and students indicate that they can turn on a radio set. However, surprisingly even though teachers and students have the required ICT skills to use the radio, results show that they are not familiar with radio use in teaching and learning contexts. This could be because radio has mainly been known to offer information and entertainment and is rarely used as a teaching tool in formal education. These results imply that there is a need for educators and instructional designers to devise ways of integrating radio as a formal educational tool in the education system.

Concerning the management of basic computer applications, results indicate that on average teachers have the necessary skills. Teachers and students can properly turn on 
and shut down a computer. Most teachers and students can move a file from a hard drive to a USB drive. The results indicate that they can move podcasts from a desktop computer to their mobile devices. These ICT competencies could be attributed to the improved ICT infrastructure and training of academic staff in basic ICT skills at MMU supported by the VLIR UOS project. However, over half of the teachers and students were found to lack the required skills for recording and editing sounds. This poses a challenge to the development of audio content, especially for teachers, and thus more training in those aspects is required if audio media is to be effective as an e-pedagogical instructional strategy in distance education.

An investigation of teachers' and students' management of podcasts shows that most teachers and fewer than half of the students know how to make podcasts, and how to upload a podcast on the Moodle platform. Results also indicate that most teachers and students have adequate ICT skills to download podcasts onto their mobile devices. There are perhaps two reasons why students scored low when it comes to making podcasts and uploading them onto the Moodle platform. The first is that, whereas teachers were trained in the two aspects, students were trained in other aspects such as how to access and sign in to the Moodle platform and how to download podcasts onto their mobile devices. The second reason is that students, unlike some teachers, have not had the opportunity to use audio media in an education setting, tt is a new instructional methodology for them. The findings of the present study challenge instructional planners and institutional administrators who wish to introduce audio media as a medium of instruction, to think and plan in terms of training teachers and students in ICT, but also to plan and allocate resources for design and production of audio content.

\subsection{Teachers' and students' levels of confidence and self-evaluation of their own ICT skills}

Students and teachers were asked if they had confidence regarding computer use. Results show that on average teachers and students have high levels of confidence in this respect. Our findings concur with Fetter (2009), where students were found to be most confident in their internet, word processing, and systems operations. High levels of confidence could be explained by the fact that every teacher was provided with a laptop from Close the Gap donation made to MMU. Perhaps the regular practice and familiarization with computer laptops gives them confidence. As for the students' confidence, it could be the result of the knowledge and skills obtained from the introduction to computer courses done by all the students enrolling at MMU. Regarding internet literacy, the students reported a higher level of literacy compared to teachers. The internet literacy levels of students are also sufficient to allow students to download podcasts from the Moodle platform and revise class content at their own convenience. Surprisingly, results showed a mismatch between ICT confidence levels and general ICT knowledge. Whereas both teachers and students indicated high ICT confidence levels, they scored low when it came to ICT general knowledge. This indicates that confidence does not translate into actual use of computer applications. This implies that when studying the ICT skills of students and teachers it is not enough to rely on measures of confidence. It is necessary to dig 
deeper into actual use of computer applications. Nevertheless, the findings support the adoption of audio media in distance education at MMU, as students can independently use computers and other $\mathrm{MP}_{3}$ players to revise the audio content from anywhere and anytime they want. An investigation of computer confidence of teachers and students is a key aspect for the integration of ICT in pedagogy. Therefore, education experts intending to integrate ICT in pedagogy must first boost the ICT confidence of teachers and students by strengthening ICT infrastructure and offering ICT training to both teachers and students. However, ICT confidence itself is not enough, efforts must be made to assess the practical use of computer applications by both teachers and students.

\subsection{Perceived ease of use of computer applications and frequency of use of $\mathrm{MP}_{3}$ players by} teachers and students

With regard to the ease of use of computer applications, the findings indicate that both students and teachers find the use of word processing, emails, text chatting and voice chatting extremely easy. This is not surprising because students and teachers live in an era in which social media networks and other ICTs have fully penetrated society. Today, students and teachers have more access to computers compared to 20 years ago. This ease of access and regular use perhaps gives them the confidence which translates into ease of use. However, students and teachers find the use of multimedia (audio and video) somewhat difficult. This is perhaps because audio media is not yet fully integrated in teaching and learning process, especially in the Ugandan context. Results regarding the frequency of use of $\mathrm{MP}_{3}$ players by students and teachers indicate that most of them frequently make use of $\mathrm{MP}_{3}$ players. However, more than half of both teachers and students indicate that they never use $\mathrm{MP}_{3}$ players to listen to recorded books. Using $\mathrm{MP}_{3}$ players to watch other activities related to their university education was also low, though slightly above average. These low results indicate that $\mathrm{MP}_{3}$ players are mostly used by both students and teachers for non-academic rather than academic purposes. This is also shown by the high percentages of some responses from students, such as those related to listening to music, watching short video clips and watching movies. This regular use of $\mathrm{MP}_{3}$ players by both students and teachers (but for entertainment rather than academic purposes) is an indication that $\mathrm{MP}_{3}$ players are popular among teachers and students and can easily be adopted in teaching and learning as educational tools. Based on these findings educators and instructional planners at higher institutions of learning should seriously consider integrating $\mathrm{MP}_{3}$ players in teaching and learning as educational tools that can support e-pedagogical practices, particularly audio media.

\section{Conclusions and recommendations}

From the findings of this study, it can be concluded that both teachers and students have adequate ICT skills. This can be seen as an indication that they are in a better position to use audio media in distance education because unlike other modern technological didactical innovations, this medium only requires knowledge and skills of basic computer applications. Results also show a high level of confidence among teachers and students and this indicates that this teaching methodology can be adopted and used 
by MMU to teach higher education distance students scattered over broad geographical areas in the Rwenzori region in Uganda. The findings indicate that teachers and students have adequate ICT skills required for ICT use in education. This is consistent with the work of Ozdemir (2017), who emphasizes that teachers' ICT proficiency levels are the most important determinants of ICT use in the educational setting. However, results show that teachers and students have insufficient knowledge regarding recording and editing audio content. We thus recommend more training and workshops on how to record and edit sounds, if the teaching methodology is to be successful. Regarding the management and storing of files, both teachers and students have the required proficiency and thus can manage to save and later find the downloaded podcasts for study purposes and future reference. Since results show that teachers and students regularly use $\mathrm{MP}_{3}$ players for purposes other than education, we are confident that they can easily adapt them for teaching and learning purposes and we recommend that instructional planners should encourage students and teachers to regard $\mathrm{MP}_{3}$ players as educational tools.

Although the present study has achieved its aims, there were inevitable limitations associated with a small sample size, because we only included students who had access to portable electronic mobile devices. Another limitation lies in the fact that only one University was selected for the study. These factors could limit the extrapolation of results to larger groups. In view of these limitations, further studies investigating ICT skills of teachers and students in relation to audio media in distance education should be done in more than one University and location so as to have a large number of participants and results that can be generalized.

Based on the findings of this study, we further conclude that audio media, unlike other e-pedagogical practices, requires only basic ICT infrastructure and thus it is appropriate for teaching environments with limited ICT resources. Generally, we can conclude that the findings of this study recognize the potential the teachers and students have for adopting audio media as a medium of instruction in distance education, because they have sufficient ICT skills needed in the audio media instruction.

\section{References}

Abiola, A. O. (2016). Computer Self-efficacy and Perceived ease-of-use of Personal Digital Assistants for Academic activities by Undergraduates in University of Ibadan.

Available at http://digitalcommons.unl.edu/libphilprac.

Ali, G., Haolader, F. A., \& Muhammad, K. (20I3). The role of ICT to make teaching-learning effective in higher institutions of learning in Uganda. International Journal of Innovative Research in Science, Engineering and Technology, vol. 2 (8), 406I-4073.

Aristizabal, A. (2009). Podcasting: a preliminary classroom study. GiST Education and Learning Research Journal, (3), 30-40. Available at https://doi.org/I0.268I7/issn.I692-5777.

Bindu, C. N. (2017). Attitude towards, and Awareness of Using ICT in Classrooms: A Case of Expatriate Indian Teachers in UAE. Journal of Education and Practice, vol. 8(I), I0-17.

Chih-Horng, K. E., Huey-Min, S. U. N., \& Yuan-Chi, Y. A. N. G. (2012). Effects of user and system characteristics on perceived usefulness and perceived ease of use of the web-based classroom response system. TOJET: The Turkish Online Journal of Educational Technology, II(3). 
Cretchley, P. (2007). Does computer confidence relate to levels of achievement in ICT-enriched learning models? Education and Information Technologies, vol. I2 (I), 29-39.

Fetter, M. S. (2009). Graduating nurses' self-evaluation of information technology competencies. Journal of Nursing Education, vol. 48 (2), 86-9o.

Hennessy, S., Onguko, B., Harrison, D., Ang’ondi, E. K., Namalefe, S., Naseem, A., \& Wamakote, L. (2010). Developing the use of information and communication technology to enhance teaching and learning in East African schools: Review of the literature. Centre for Commonwealth Education \& Aga Khan University Institute for Educational Development-Eastern Africa Research Report, I.

Hoover, A., \& Krishnamurti, S. (2010). Survey of college students' MP3 listening: Habits, safety issues, attitudes, and education. American journal of audiology, vol.i 9 (I), 73-83.

Jamieson-Proctor, R. M., Burnett, P. C., Finger, G., \& Watson, G. (2006). ICT integration and teachers' confidence in using ICT for teaching and learning in Queensland state schools. Australasian Journal of Educational Technology, vol. 22 (4).

Kilic, D. B. Ç. (2017). Examining music teachers' self-confidence levels in using information and communication technologies for education based on measurable variables. Educational Research and Reviews, vol. I2 (3), IOI-I07.

Li, J., Snow, C., \& White, C. (2015). Urban adolescent students and technology: Access, use and interest in learning language and literacy. Innovation in Language learning and teaching, 9 (2), I43-I62.

Martyn, S. (2008). Quantitative Research Design. Retrieved Jan 03, 2018 from Explorable.com: https://explorable.com/quantitative-research-design.

Myers, K. M., \& Wilson, B. G. (2000). Situated Cognition in Theoretical and Practical Context. In D. Jonassen, \& L. S. M., Theoretical Foundations of Learning Environments (pp. 57-88). New Jersey: Lawrence Erlbaum Associates, Inc.

Neema-Abooki, P. A., \& Rukia, N. (2015). Usability of Computers in Teaching and Learning at Tertiary-level Institutions in Uganda. African Journal of Teacher Education, vol. 4 (I).

Orinda, O. E. (2015). Usability of Information and Communication Technology facilities and e-pedagogical practices within selected universities in Kla Uganda. Global Journal of advanced Research, vol. 2 (6).

Özdemir, S. (2017). Teacher Views on Barriers to the Integration of Information and Communication Technologies (ICT) in Turkish Teaching. International Journal of Environmental and Science Education, vol. I2 (3), 505-521.

Paraskeva, F., Bouta, H., \& Papagianni, A. (2008). Individual characteristics and computer self-efficacy in secondary education teachers to integrate technology in educational practice. Computers \& Education, vol. 50 (3), ro84-I09I.

Schlag, M., \& Imhof, M. (2017). Does Perceived Ease of Use Mitigate Computer Anxiety and Stimulate Self-Regulated Learning for Pre-Service Teacher Students? International Journal of Higher Education, vol. 6 (3), I54.

Stiler, G. M. (2007). MP3 players: Applications and implications for the use of popular technology in secondary schools. Education, vol. I28 (I), 20-34.

Šumak, B., Heričko, M., Pušnik, M., \& Polančič, G. (20II). Factors affecting acceptance and use of Moodle: An empirical study based on TAM. Informatica, vol. 35(I).

Sumande, C. T., Castolo, C. L., \& Comendador, B. E. V. (2016). The ICT Level of Confidence of Course Specialists in Distance Education: The Polytechnic University of the Philippines Experience. Turkish Online Journal of Distance Education, vol. 17 (4). DOI: I0.17718/tojde.25498.

Tasir, Z., Abour, K. M. E. A., Halim, N. D. A. \& Harun, J. (2012). Relationship between Teachers' ICT Competency, Confidence Level, and Satisfaction toward ICT Training Programmes: A Case Study among Postgraduate Students. Turkish Online Journal of Educational Technology, vol. II (I), I38-I44. Retrieved February I7, 2018 from https://www.learntechlib.org/p/55801/.

Teo, T. (2009). The impact of subjective norm and facilitating conditions on pre-service teachers' attitude toward computer use: A structural equation modeling of an extended technology acceptance model. Journal of Educational Computing Research, vol. 40(I), 89-I09. 
Varol, F. (2013). Elementary school teachers and teaching with technology. TOJET: The Turkish Online Journal of Educational Technology, vol. I2 (3), 85-90.

Walls, S. M., Kucsera, J. V., Walker, J. D., Acee, T. W., McVaugh, N. K., \& Robinson, D. H. (2010). Podcasting in education: Are students as ready and eager as we think they are? Computers \& education, vol. 54(2), $371-378$.

Williams, M. R., Warner, W. J., Flowers, J. L., \& Croom, D. B. (2014). Accessibility and Usage of Technology by North Carolina Agriculture Teachers. Journal of Agricultural Education, vol. 55 (4), I9I-205.

Yildirim, S. (2007). Current utilization of ICT in Turkish basic education schools: A review of teacher's ICT use and barriers to integration. International Journal of Instructional Media, vol. 34 (2), I7I. 